\title{
Erratum to: Application of ionic liquid to a high-performance calcium-resistant additive for filtration control of bentonite/water-based drilling fluids
}

Lili Yang ${ }^{1,2, \star}$, Guancheng Jiang ${ }^{1,2}$, Yawei Shi ${ }^{1,2}$, Xin Lin $^{1,2}$, and Xiao Yang ${ }^{2}$

'State Key Laboratory of Petroleum Resources and Prospecting, China University of Petroleum (Beijing), Beijing 102249, China

${ }^{2}$ MOE Key Laboratory of Petroleum Engineering, China University of Petroleum (Beijing), Changping District 102249, Beijing, China

Published online:

22 February 2017

(C) Springer Science+Business Media New York 2017

\section{Erratum to: J Mater Sci}

DOI 10.1007/s10853-017-0870-7

In Scheme 1, the structural formula of first segment [poly (acrylamide)] in the copolymer was incorrect; the carbonyl group was missing. It is correct in the revised scheme below. In Table 2 , the correct heading for the first column should be concentration of PASV [C(PASV) (wt \%)]. Also, the entries for the first column should be written as $0.5,1.0,1.5,2.0,2.5,3.0$ for consistency with the data in the text. The authors regret these errors and any confusion they may have caused the readers. The corrected versions of the Scheme 1 and Table 2 follow.

The online version of the original article can be found under doi:10.1007/s10853-017-0870-7.

Address correspondence to E-mail: yangll@cup.edu.cn 


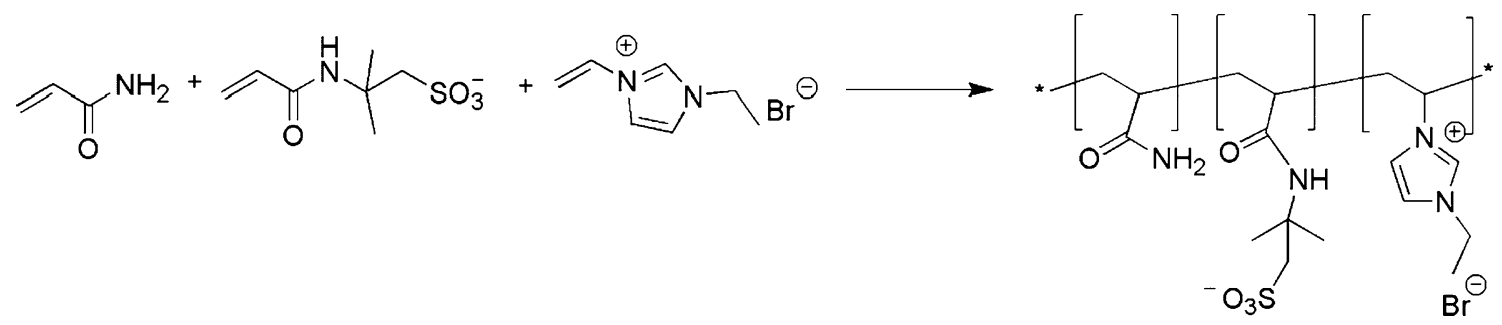

Scheme 1 Systematic diagram for synthesis of copolymer of AM, AMPS, and VeiBr.

Table 2 Rheological and filtration properties of BT/ $11 \mathrm{Ca}-\mathrm{WDF}$ with different PASV copolymer concentrations at $25{ }^{\circ} \mathrm{C}$

\begin{tabular}{|c|c|c|c|c|c|c|}
\hline $\mathrm{C}(\mathrm{PASV})(\mathrm{wt} \%)$ & $\mathrm{AV}(\mathrm{mPa} \mathrm{s})$ & $\mathrm{PV}(\mathrm{mPa} \mathrm{s})$ & $\mathrm{YP}(\mathrm{Pa})$ & $\mathrm{Gel}_{\text {in }}(\mathrm{Pa})$ & $\operatorname{Gel}_{10 \min }(\mathrm{Pa})$ & $\mathrm{FL}(\mathrm{mL})$ \\
\hline 0.5 & 7 & 5.5 & 1.5 & 2 & 4 & 73.6 \\
\hline 1.0 & 10 & 10 & 0 & 0.5 & 0.5 & 9.9 \\
\hline 1.5 & 32 & 24 & 8.2 & 2 & 6 & 5.2 \\
\hline 2.0 & 45 & 32 & 13.3 & 2.5 & 7.5 & 4.8 \\
\hline 2.5 & 73 & 49 & 24.5 & 3 & 7.5 & 5.3 \\
\hline 3.0 & 94 & 63 & 31.7 & 3.5 & 7.5 & 4.8 \\
\hline
\end{tabular}

C (PASV) concentration of PASV; FL fluid loss 